\title{
Research on the Effects and Problems of Implementing Environmental Tax in Hubei Province
}

\author{
Yang Ping \\ Wuhan Business University, Wuhan, 430056, China \\ E-mail: 1107915561@qq.com
}

Keywords: Environmental tax; Implementation; Effects; Problems

\begin{abstract}
As the reform of environmental tax in Hubei has been gradually put into action, analysis of the effects and problems of such tax becomes increasingly important. Supported by relevant theories, this paper will introduce its advantages as a market method in environmental management and summarize its deficiencies at this stage by combining the results of empirical analysis. Based on the successful experiences of other countries, the author will systematically discuss the tax collection in Hubei and offer some advice with regard to the specific design and collection of the tax.
\end{abstract}

\section{Introduction}

As a rare resource of human society, the environment has a unique social and economic value. [1] However, people have paid much price for the excessive consumption of these resources and the deteriorating environment when striving for the rapid development of industrialization. Since the reform and opening up in 1978, China's economy has been growing at an average annual rate of about $9.5 \%$ which is inevitably accompanied by such environmental problems as high resource consumption and environmental deterioration. [2] Ecological disruption, environmental pollution and resource exhaustion not only cause irretrievable damages to our economic growth but also pose a threat to the life, work and health of people. In this way, we give a top priority to the collection of environmental tax. [3] The concept of the tax, dating back to 1920s, was put forward by the British economist Pigou in his Spillover Effect: In a narrow sense, it mainly includes air and water pollution tax, solid waste and noise pollution tax, while in a broad sense; it mainly covers the tax on pollutants, pollution behaviors and resources.

\section{Necessity for implementing the environmental tax}

Tax collection on the environment can both reduce energy consumption and environmental pollution. [4] It mainly reflects in the following two aspects: Firstly, Environmental tax levied in intermediate input link, such as the collection of carbon tax on oil and coal, may lead to higher corporate costs and eventually keep the product price growing through tax shifting. Secondly, the collection of the tax in the final consumption stage, such as fuel tax in the consumption tax, may cause a rise in the prices of consumer goods. The essence of the two ways is to make a change in social behaviors through a floating price. [5] For the enterprise, while seeking for other inputs with free or low tax as a substitution, it will carry out a research on energy-saving technology in the long haul in ways to make environmental inputs and relevant outputs more sustainable. Likewise, consumers will also reduce consumption in green products and search for other environmental-friendly products as a replacement. That is how we can stimulate the needs for those products and the growth of green industry in order to foster the economic transformation and growth.

\section{Benefits of implementing environmental tax in Hubei}

Three benefits are brought about by the tax through its function: Firstly, environmental benefits. 
Levying the tax can greatly reduce the emission of targeted pollutants. Secondly, it is economic benefits. It can advance innovations in green technology and promote the growth of high-tech industry, thus transforming the economic growth pattern. Thirdly, it is social benefits. It can regulate consumer behaviors and spread green consumption to the whole society so as to enhance the well-being of all mankind.

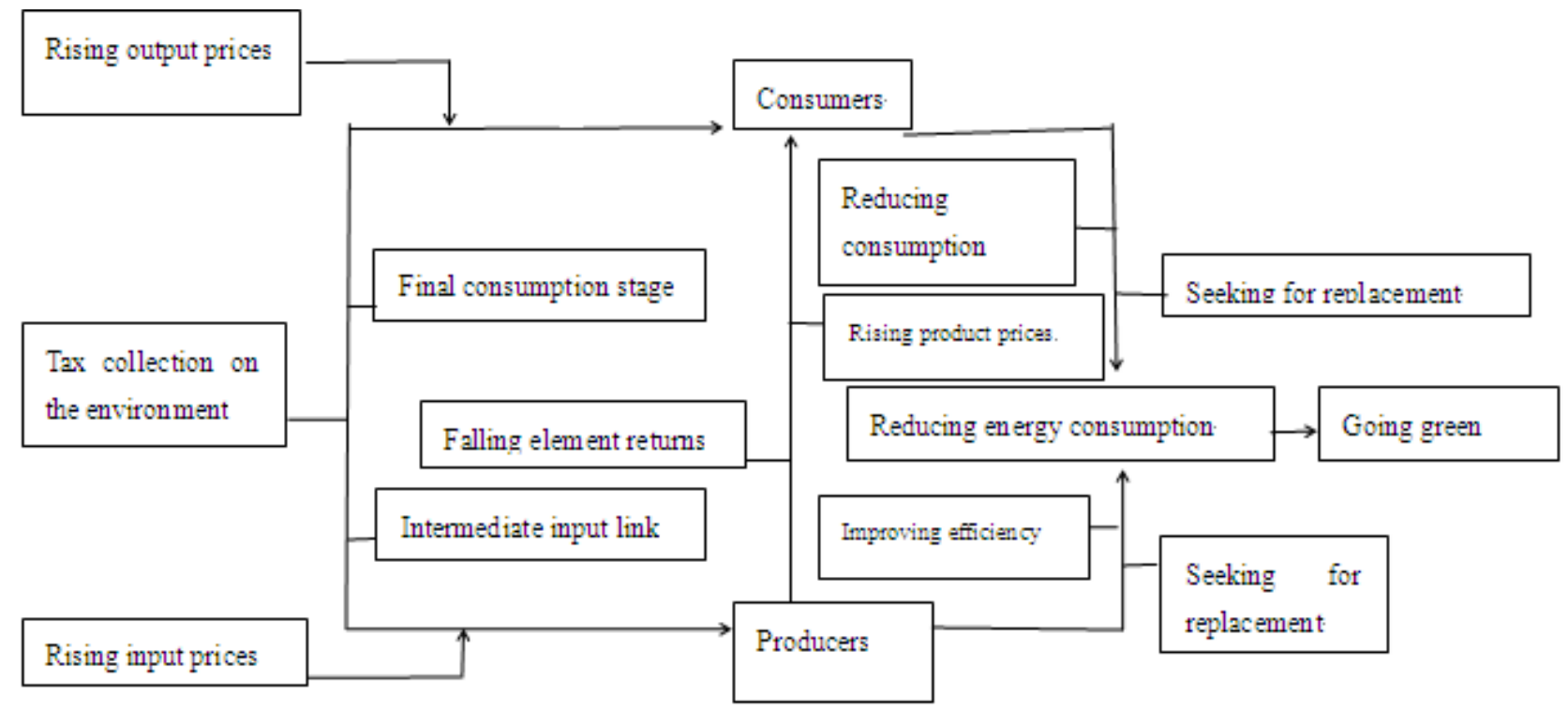

Fig. 1 The process of implementing environmental tax

\section{Effects of implementing environmental tax in Hubei}

\subsection{Environmental effects}

Since the reform and opening up, the environmental pollution in this area has become more severe with the growing economy and population as well as the accelerated industrialization and urbanization. Levying the tax will substantially reduce the emission arising from the targeted pollutants so as to achieve the goal of going green. As the ecological environment is vulnerable, it's hard to restore after being destroyed deliberately. As an important economic method and long-term mechanism for environmental pollution, the policy must be put into effect to control pollution, adapt to the grim situation and cope with the pressure from climate change. With limited natural resources, the tax system must be established to make possible the environmental protection and reasonable use of resources.

\subsection{Economic effects}

The exceedingly rapid growth of high energy-consuming and high-pollution industries has not yet been fundamentally curbed amid the growing economy of Hubei. Faced with old environmental problems and growing pressure of the new problems, we have an increasingly prominent contraction between the socio-economic development and limited resources. By applying the tax, Hubei has promoted innovations in green technology, fueling the growth of high-tech industry. By doing so, the energy price continues to soar in developed countries, making many sustainable products and processes available to enterprises and residents. Thus, for many industries, environmental tax means "cost" while it represents a profit opportunity for industries involved in developing, manufacturing and selling green products. Additionally, needs for such products will promote the growth of high-tech industries, forming a new driver for economic development. According to the economic analysis of the environmental policy, the policy can bring about innovations needed for low environmental damage and high productivity and make the emerging industries grow and thrive. 


\subsection{Social effects}

The government has remained committed to keeping macro tax burden stable, improving social welfare and reducing political resistance while collecting environmental tax. When collecting or raising the tax, other taxes should be cut down so as to ensure the overall tax burden remains the same. As an environmental regulator, the local government has been restricting environmental pollution and disruption mainly through administrative orders. However, the management model overemphasizes the authority and leadership of the government but regards enterprises as a passive observer, ignoring their initiative in environmental protection. For this reason, the tax system can be built by improving laws and regulations and developing green philosophy. That means we can restrain, motivate or guide behaviors of governments, organizations, enterprises and individuals as well. On the one hand, the tax has both income effect and substitution effect. The local authority can regulate the behaviors of producers and consumers, foster green production and consumption so as to encourage social engagement in green activities. On the other hand, Hubei combines the tax with its expenditure system, which can not only restrict resource wastes and environmental pollution but also enable enterprises to take the initiative to innovate manufacturing processes and apply green technology. The establishment of such system can help protect the environment in ways that change from following the mandatory orders of the government to leverage the initiative of individuals so as to develop a new generation of green philosophy and a society of frugality.

\section{Problems in implementing environmental tax in Hubei}

Up to now, the implementation of the tax has not obviously enhanced emissions and treatment of pollutants and failed to meet the expectations. The paper holds that there are three problems in this regard.

\subsection{Insufficiency of sewage charge policy}

The policy carried out by Hubei has not achieved productive results. On the one hand, the policy itself has obvious defects; On the other hand, it is exposed to external factors in the operational process.

\subsection{Lack of environmental tax in main taxes}

The few taxes and low tax revenue concerning the environment in the current tax system in Hubei lead to less fruitful results in environmental protection. Resource tax only includes crude oil, natural gas, coal, salt, non-metal ores, ferrous metal ores and non-ferrous metal ores. Accounting for a small part, other resources like urban construction tax, urban land use tax and land occupation tax have limited capabilities in protecting the environment.

\subsection{Empty preferential tax policy in environmental protection}

Taxes and relevant preferential tax policy regarding the environment are few as the tax system in this area focuses less on environmental protection. Moreover, the enjoyment of the policy is largely subject to external factors.

\section{Conclusions}

The tax collection is an important economic method for strengthening environmental protection and addressing climate change and is also an significant content of the improvement of the system during the 13th Five-Year Plan in Hubei The paper introduces the basic theory about the tax, analyses the effects and benefits of the system and points out the problems in the tax collection and charge system. In this way, we can see the advantages and disadvantages in the policy and give more guidance in the tax reform, which is beneficial to improve the policy. Specifically, collecting the tax avenue in Hubei should use the following methods: Firstly, we should focus on the tax rebates of key industries and subsidies on low income groups. Secondly, we should focus on developing green technology, controlling pollution and countering climate change while taking into 
account of the use of pollution charge. Thirdly, in the approaches of using, we should take more indirect preferential ways like financial discount to bring the tax into full play.

\section{Acknowledgements}

In this paper, the research was sponsored by Wuhan Business University, and the Project Name is Research on the Effects and Problems of Implementing Environmental Tax in Hubei Province (Project No.2017KY005).

\section{References}

[1] Increasing carbon and material productivity through environmental tax reform[J] . Paul Ekins, Hector Pollitt, Philip Summerton, Unnada Chewpreecha. Energy Policy. 2011

[2] The double dividend from carbon regulations in Japan[J]. Shiro Takeda. Journal of The Japanese and International Economies. 2006 (3)

[3] Environmental tax reform and the double dividend: A meta-analytical performance assessment[J] . Roberto Patuelli, Peter Nijkamp, Eric Pels. Ecological Economics. 2005 (4)

[4] Performing an environmental tax reform in a regional economy. A computable general equilibrium approach[J] . Francisco J. André, M. Alejandro Cardenete, Esther Velázquez. The Annals of Regional Science. 2005 (2)

[5] Optimal Taxation in the Presence of Externalities. Sandmo, A. Swedish Journal of Economics. 1975 